\title{
A DISTRIBUIÇÃO DOS SUBSTANTIVOS EM GÊNERO: UMA PROPOSTA DIDÁTICA
}

\author{
José Mario Botelho (UERJ e ABRAFIL) \\ botelho_mario@hotmail.com
}

\section{Introdução}

Ultimamente, o assunto acerca da variação de gênero dos nomes portugueses tem recebido uma atenção considerável, porquanto alguns estudiosos vêm manifestando-se, de maneira crítica, em relação ao assunto.

Em língua portuguesa, além dos nossos trabalhos (BOTELHO, 2005 e 2007), temos as valiosas digressões de: Câmara Jr. (1972, p. 115-29, e em outros trabalhos), Herculano de Carvalho (1973, p. 49-59, e em outros trabalhos), Martin (1975, p. 3-8), Sandmann (1991, p. 36-40), Bechara (1999, p. 131-3) e Azeredo (2000, p. 107-12); e em língua estrangeira: Hjelmslev (1971, p. 22058), Matthews (1974, p. 37-58) e Jespersen (1975, p. 226-43).

Bem antes de 1972, em artigos para a Revista Vozes, que, pouco mais tarde (1967), foram reunidos num pequeno volume, intitulado Problemas de linguística descritiva, Câmara Jr. já tinha demonstrado a sua preocupação com o assunto. Depois, em seus Dispersos (1972), descreveu a imanência do gênero nos substantivos do português e acusou algumas inconsistências que se formaram em torno da noção de gênero gramatical.

Contudo, ainda há muitos estudiosos repetindo a abordagem tradicional, que concebe um fenômeno de flexão a variação de gênero dos nomes substantivos em português, até mesmo Câmara Jr., embora os textos tradicionais acerca do assunto não resistam a uma leitura crítica mais aprofundada. Logo surgem elementos importantes para a constatação de que o assunto não é tão simples como nos parece ser e que o tratamento a ele dispensado precisa ser revisto.

A confusão entre sexo e gênero é uma das maiores inconveniências no tratamento deste assunto por parte da Tradição. 
A falta de observação do caráter imanente do gênero do substantivo, para o qual nos alertou Câmara Jr., ou a falta de compreensão desse aspecto, até mesmo por parte do próprio Câmara Jr., que afirmou em seus trabalhos ser flexão os casos em que a formação de feminino se faz com a troca da vogal temática "-o" pela marca de gênero "-a", é outro fator importante da contestável abordagem tradicional.

\section{A distinção entre a noção de sexo e gênero nos nomes substan- tivos}

Considerações gerais sobre a distinção entre sexo e o gênero dos substantivos, de maior clarividência, formulou Câmara Jr. em seus Dispersos.

O autor, demonstrando serem distintas a noção de sexo e a noção de gênero nos nomes substantivos, praticamente estabeleceu "as maneiras de se processar a integração de todos os substantivos no seu quadro de gênero" (1972, p. 116).

Uma das maneiras, segundo ele, á a "analogia formal", a qual se refere à terminação. Assim, um substantivo será masculino ou feminino, de acordo com a forma de sua terminação. Outra maneira é a analogia conceptual, que se refere à significação, que, no caso de certos nomes de coisas ("espinho/espinha", "jarro/jarra" etc.), ou seja, metáforas, se ligam à cultura em que a língua se efetiva. Desse modo, a analogia conceptual se liga à analogia formal (1985, p. 138). A outra maneira é a ampliação do gênero, que se refere à "flexão". Esta é semanticamente motivada, arbitrária e convencional. Todas, contudo, tendem a fazer do gênero muitas vezes uma simples divisão mórfica.

De fato, no tratamento do gênero, não convém se limitar a uma dessas noções, que se nos parecem precisas e bem definidas. Principalmente, nas duas últimas, que se associam mais intimamente à visão de mundo e que sugerem uma motivação semântica da língua. 
Na descrição gramatical do gênero, a utilização de um critério de natureza semântica fatalmente se nos mostrará ineficiente e limitado, por não abarcar todos os nomes substantivos da língua.

O sexo, que é uma noção de natureza semanticamente motivada, para a língua portuguesa, que distribui seus substantivos em masculinos e femininos, não constitui nem mesmo um critério satisfatório. O critério semântico do sexo só se aplica aos substantivos relacionados ao mundo animal; e ainda aí, somente se aplica a alguns nomes, em que se pode observar uma correspondência entre a noção sexual e a noção genérica gramatical, já que há um número considerável de nomes em que a noção semântica do sexo se obtém com o acréscimo das palavras "macho" ou "fêmea".

O gênero, que é uma noção de natureza puramente gramatical, se estabelece de forma imanente - todos os nomes substantivos são iminentemente masculino ou feminino -, e se efetiva com o uso do artigo ou outro determinante que o acompanha.

Logo, tal critério semântico não coincide plenamente com a noção gramatical do gênero em si, sendo, pois, inconveniente adotálo ou sequer considerá-lo na descrição e distribuição dos substantivos em gênero.

Tal descrição e distribuição já conta com outros processos lexicais eficientes - derivação lexical (ex.: menino - menina; conde condessa; galo - galinha), transformação de elementos terminais (ex.: embaixador - embaixatriz; ator - atriz), supressão (ex.: cidadão - cidadã; lebrão - lebre), alternância vocálica (ex.: avô - avó; vovô vovó), estruturação sintagmática (ex.: a cobra macho - a cobra fêmea; o macho do jacaré - a fêmea do jacaré), comutação de determinante (ex.: o artista - a artista; um estudante - uma estudante) e heteronímia (ex.: boi - vaca; homem - mulher) -, o que torna o critério semântico do sexo despropositado, apesar de sua importância como um traço semântico na visão cósmica da língua, que deve ser explorado em outro tipo de estudo. 


\section{A imanência do gênero do substantivo em português}

Primeiramente, convém ressaltar que o gênero é uma noção gramatical, como observamos anteriormente, e que constitui, como categoria gramatical, um dos traços flexionais menos convenientemente descritos nos estudos gramaticais em língua portuguesa. Daí, ter sido uma preocupação de Câmara Jr. e de outros, citados na nossa introdução, e estar despertando o interesse de tantos estudiosos atualmente.

A categoria gramatical de gênero, assim como outras (a de número, nos substantivos; a de gênero e número, nos adjetivos e em certos tipos de pronomes; e a de modo e tempo e número e pessoa, nos verbos), não recebeu um tratamento satisfatório em nossas gramáticas, porquanto o fenômeno da flexão (em que ela se insere) praticamente não foi bem explorado.

Quanto ao gênero do substantivo, a complexidade do assunto é ainda maior, em virtude do caráter imanente do gênero desta classe de palavras, que desafia a técnica descritiva tradicional com que aqueles desatentos à imanência do gênero do substantivo tentaram, em vão, minimizar a dificuldade do assunto em si.

De fato, conceber o gênero imanente dos substantivos é negar o status de categoria gramatical do gênero nos nomes substantivos em português ou é, pelo menos, pôr em questionamento as descrições existentes. A afirmação de que o gênero é uma categoria gramatical - traço flexional - nos leva a aceitá-lo como sendo um conceito de gramática e, consequentemente, uma noção que o falante não cria.

Quando se deseja denominar um referente feminino, o usuário ou se vale de uma denominação já conhecida ou da denominação existente do masculino e lhe acresce uma marca de feminino, sob regras preestabelecidas ou, o que é menos provável, cria uma nova denominação no feminino. Já o adjetivo concorda com o substantivo a que se liga; processo esse de caráter obrigatório e sistemático.

Diferente dos adjetivos, todos os substantivos em português têm um gênero pré-estabelecido, considerando a especificidade dos substantivos do tipo "o/a artista", "o/a estudante" e outros (tradicionalmente considerados comuns de dois), a serem determinados pelo 
contexto, os quais necessitam do traço pragmático (conhecimento de mundo do falante) para o reconhecimento de seu gênero.

Em "Considerações sobre o gênero em português" (1972, p. 115-29), o próprio Câmara Jr., que inusitadamente concebe a flexão de gênero nos substantivos, admite a natureza lexical e o caráter imanente do masculino e feminino de certos substantivos, apesar de conceber num pequeno número deles, de tema em "-o", a flexão.

Verifica-se nessa sua concepção uma inconsistência, pois o que se constata é que um número comprovadamente majoritário dos substantivos apresenta gênero imanente e somente uma minoria em relação ao léxico da língua, valendo-se da forma-base, apresenta uma forma de masculino, com o acréscimo da vogal temática "-o", e outra de feminino, com o acréscimo do sufixo "-a".

Sobre o caráter de imanência do gênero dos substantivos, afirma: "Em outros substantivos, não há flexão de gênero. $O$ caráter masculino ou feminino da palavra está imanente na palavra e é de natureza lexical, não flexional". (CÂMARA Jr., 1985, p. 77)

Comprovamos (BOTELHO, 2004, p. 11-6) valer para toda a classe dos substantivos o que afirma Câmara Jr. nesse fragmento, de sua História e estrutura da língua portuguesa, referindo-se a uma parte deles, cujos dados constatam ser a maioria dos substantivos.

Em relação a essa imanência, já nos alertava o autor, em seus Dispersos, para o fato de ser imanente a expressão de gênero dos substantivos em português:

Como, por outro lado, todos os substantivos em português têm um gênero determinado, dependente ou independente do contexto, há que concluir que não é a flexão do substantivo, em princípio, a marca básica do seu gênero. Com efeito, quer apareça, quer não apareça a flexão, todo nome, em cada contexto, será imperativamente masculino ou feminino. (Idem, 1972, p. 121)

Apesar de Câmara Jr. digressionar claramente sobre o gênero imanente dos substantivos, nesse em muitos outros textos, concebe a flexão de gênero nessa classe. $\mathrm{O}$ autor afirma ser a formação de gênero dos substantivos uma flexão, apesar de conceber a sua imanência, criando uma incoerência, uma vez que não esclarece como isto pode ser possível. 
O feminino de alguns nomes substantivos é, em português, uma forma marcada pelo acréscimo da marca "-a", à semelhança do processo que se verifica nos adjetivos, uma particularização mórficosemântica do gênero masculino.

As nossas Gramáticas, além de confundir as noções de sexo e de gênero, concebem uma oposição equipolente na flexão de gênero; contudo, não constitui o "-o" uma marca de masculino, porquanto não é privativa tal oposição, uma vez que o mecanismo de formação do feminino não é único, nem geral (ao lado do par "lobo/loba", há os pares "mestre/mestra" e "autor/autora", além dos diversos processos de formação).

Também descrevem sob um mesmo tópico - "flexão de gênero" - a formação de feminino a partir da marca "-a", da sufixação lexical com outros sufixos, da eliminação de elementos terminais, da alternância vocálica, de estruturação sintagmática e da heteronímia.

Logo, estabelece-se uma verdadeira confusão em virtude da má compreensão do assunto acerca da formação de gênero do substantivo e, em momento nenhum, demonstram conceber que a imanência do gênero, como vimos repetindo, é uma característica geral desta classe, enquanto a tal flexão é particular a alguns.

Conceber o gênero imanente e distinguir sexo (gênero nocional) de gênero gramatical constituem o primeiro passo e o mais relevante para se negar a flexão de gênero dos substantivos (como um fenômeno sistemático) ou, pelo menos, para se verificar a complexidade do tema, já que não é a correspondência de sexo, e sim o acréscimo da marca de gênero ("casa bela", "torta gostosa"), imposta pela estrutura frasal, que cria o fenômeno gramatical, que se dá fundamental e especialmente nos adjetivos e em certos pronomes em função adjetiva.

\section{Proposta didática para a apresentação gênero dos substantivos}

Sem dúvidas nenhuma, a flexão de gênero nos nomes constitui um dos tópicos mais confusos e incoerentes de nossas gramáticas tradicionais. Duas são as causas para o problema: uma de ordem semântica e outra de interpretação teórica. 
Para explicarmos o problema de ordem semântica, que criou uma verdadeira confusão entre sexo e gênero gramatical, observamos que se pode constatar a falta de coincidência entre esses dois aspectos. Há nomes gramaticalmente femininos ou masculinos que servem para ambos os sexos sem qualquer indicação (ex.: o cônjuge; a criança; o jacaré; a cobra). No caso dos dois últimos - denominados "epicenos" -, mesmo quando acrescidos da indicação do sexo (com a aposição do nome substantivo "macho" ou "fêmea"), a palavra continua com o mesmo gênero gramatical, indicado pelo determinante (artigo) de masculino ou de feminino.

Quanto ao problema da interpretação teórica, ressaltamos que, nos nomes de gênero único (masculinos e femininos), a marca de gênero está tão somente na forma do artigo que exigem. No caso dos que recebem a marca lexical de feminino "-a" (que é um sufixo), essa indicação, que é concomitante, deve ser considerada redundante.

A solução para o problema está na concepção do gênero imanente e na distinção entre o gênero nocional (sexo) e o gênero gramatical.

Não ocorre o fenômeno da flexão de gênero nos substantivos, posto que não se trata de um fenômeno sistemático, e não há fundamentalmente uma correspondência entre sexo e gênero. $\mathrm{O}$ processo de formação de feminino dos substantivos com o acréscimo da marca de gênero difere do dos adjetivos. Nestes, o processo é sistemático, fechado e obrigatório; dá-se pelo fenômeno da congruência, imposto pela natureza da frase, uma vez que todo o adjetivo deve concordar em gênero e em número com o núcleo substantivo.

Aliás, substantivos e adjetivos, apesar de ser lábil tal classificação, se distinguem na base da flexão de gênero: aqueles não sofrem a referida flexão, enquanto estes a sofrem para concordar com o núcleo substantivo a que se refém.

As gramáticas tradicionais expõem o tema de maneira incoerente e confusa, principalmente no que se refere à distribuição dos substantivos em gênero, a qual poderia ser ensinada na base da forma masculina ou feminina do artigo, que é exigido por eles.

Tal abordagem, de certa forma, anuncia uma proposta didática para a apresentação de gênero dos substantivos, a partir da forma 
masculina ou feminina do artigo exigido, que Câmara Jr. (1985, p. 82) esboça e reformulamos (BOTELHO, 2004, p. 43-5).

Segundo Câmara Jr., a distribuição dos substantivos em gênero seria a seguinte:

1) Nomes substantivos de gênero único: o carro, a casa, o algoz, a testemunha, o jacaré, a cobra;

2) Nomes de dois gêneros sem flexão redundante: o/a estudante, o/a artista, o/a mártir; e

3) Nomes substantivos de dois gêneros com flexão redundante: o lobo/a loba, o mestre/a mestra, o autor/a autora.

Concordamos com a sugerida distribuição, com uma pequena alteração, por não concebermos a flexão de gênero nos nomes substantivos. Portanto, sugerimos substituir na proposta de Câmara Jr. a palavra "flexão" por "formação".

Entretanto, para tornar ainda mais didática a temática, a partir de uma distribuição dos substantivos portugueses em gênero, em que se pode constatar que todo e qualquer substantivo da língua apresenta um gênero pré-determinado (masculino ou feminino) mormente pelo artigo (determinante por excelência), apresentamos a seguinte classificação genérica dos substantivos, de forma simples e sintética.

1) substantivos de gênero pré-determinado, independente do contexto:

a) masculinos - os que recebem a anteposição do artigo "o" ou outro determinante.

Ex.: menino, mestre, cantor, órfão, ator, homem, cônjuge, jacaré, leão, galo, carro, lápis, jarro, porto, planeta, champanha, vatapá, cipó

b) femininos - os que recebem a anteposição do artigo "a" ou outro determinante.

Ex.: aluna, professora, atriz, mulher, órfã, condessa, criança, cobra, leoa, casa, jarra, tribo, imago, pá.

2) substantivos de gênero a ser determinado lexicalmente, dependente do contexto. 
Ex.: o/a artista, estudante, mártir, consorte, colega, paulista

\section{Considerações finais}

As contradições causadas pela descrição preconceituosa de gênero dos substantivos, devido principalmente à relação estabelecida pela tradição entre sexo e gênero gramatical, são muitas. O gênero, como já ressaltava Câmara Jr. (1972, p. 115), recebeu um tratamento inadequado pela nossa Tradição Gramatical.

No caso do substantivo, o problema é ainda maior em virtude do caráter imanente do gênero desta classe de palavras, que desafia a técnica descritiva tradicional com que aqueles desatentos à imanência do gênero do substantivo tentaram, em vão, minimizar a dificuldade do assunto em si.

Diferente dos adjetivos, todos os substantivos em português têm um gênero pré-estabelecido, que nada ou pouco tem a ver com a noção de sexo.

O fenômeno da flexão se caracteriza pelo acréscimo de uma desinência ao radical, com ou sem alteração do elemento terminal do vocábulo em questão, o qual se dá de forma sistemática e obrigatória, como o é nos adjetivos. Acresce-se, ainda, que este processo é gramatical, pois consiste em fazer variar um vocábulo para expressar certas categorias gramaticais nele.

No caso dos substantivos, apenas um número minoritário se sujeita a um processo semelhante, que é assistemático e fortuito, pois somente aqueles que se referem a determinados seres animados, com os quais se pode fazer uma relação entre sexo e gênero, podem receber o acréscimo de um elemento mórfico, semelhante àquele que é comumente classificado como desinência de gênero feminino "-a".

Nos substantivos, considerando a categoria de gênero, faz-se uma classificação arbitrária e convencional, e há mais de uma maneira de reunir todos os substantivos do português no seu quadro de gêneros: a analogia formal, a analogia conceptual (incluindo algumas metáforas) e a ampliação do gênero num dado contexto, cuja escolha é semanticamente motivada. 
O critério semântico do sexo só seria teoricamente aplicável a substantivos referentes ao reino animal, e ainda aí, há incongruências (ex.: o cônjuge, jacaré, juriti; a criança, cobra, onça e tantos outros. Palavras masculinas ou femininas gramaticalmente, mas que servem a ambos os sexos sem mudança do gênero gramatical.). Aliás, na língua portuguesa, como ocorre em outras línguas românicas, os gêneros masculino e feminino não expressam exclusiva e rigorosamente uma diferenciação sexual, que, apesar de constituir um dado relevante para uma descrição de gênero português, seria mais bem estudada em pragmática, enquanto que a noção de masculino e feminino como gêneros gramaticais importa à gramática.

Assim, o tópico gênero de substantivos em português sugere uma simples distribuição bipartida desta classe de palavras; de um lado todos os masculinos (os que podem receber a anteposição do artigo masculino "o") e do outro, todos os femininos (os que podem receber a anteposição do artigo feminino "a").

Até Câmara Jr. (1972 e 1985), devido à complexidade do assunto, propôs a flexão de gênero dos substantivos, embora tenha apresentado uma descrição consistente sobre a imanência do gênero dos substantivos - subsídio para se negar o fenômeno de flexão nos substantivos.

\section{REFERÊNCIAS BIBLIOGRÁFICAS}

AZEREDO, José Carlos de. Fundamentos de gramática do português. Rio de Janeiro: Zahar, 2000.

BECHARA, Evanildo. Moderna gramática portuguesa. 37. ed. Rio de Janeiro: Lucerna, 1999.

BOTELHO, José Mario. O gênero imanente do substantivo no português. Rio de Janeiro: Botelho, 2004.

Contribuição de Câmara Jr. para uma descrição conveniente do gênero do substantivo em português. In: Anais do XI CNLF, Vol XI, n. 12, Rio de Janeiro: CiFEFiL, 2007. p. 64-78.

CÂMARA Jr., Joaquim Matoso. Problemas de linguística descritiva. 14. ed. Petrópolis: Vozes, 1991. 

drão, 1989.

Princípios de linguística geral. 7. ed. Rio de Janeiro: PaHistória e estrutura da língua portuguesa. 4. ed. Rio de Janeiro: Padrão, 1985. 1985.

. Estrutura da língua portuguesa. 15. ed. Petrópolis: Vozes, . Dispersos. Seleção e introdução por Carlos Eduardo Uchôa. Rio de Janeiro: Fundação Getúlio Vargas, 1972.

CARVALHO, José G. Herculano de. Estudos linguísticos. 2. ed. Coimbra: Coimbra, 1984, v. 1, 2 e 3.

. Teoria da linguagem: Natureza do fenômeno linguístico e a análise das línguas. Tomo I, 3. tiragem, emendada. Coimbra: Atlântida, 1973.

JESPERSEN, Otto. The Philosophy of Grammar. London: George Allen e Unwin ltd, 1975.

MATTHEWS, P. H. Morphology. 2. ed. Cambridge: CUP, 1991.

MARTIN, John W. Gênero? Revista Brasileira de Linguística, ano $1,2^{\circ}$ semestre, 1975 , p. 3-8.

SANDMANN, Antônio José. Morfologia geral. São Paulo: Contexto, 1991.

Morfologia lexical. São Paulo: Contexto 1992. 